\title{
Fire-Fighting and Hazardous-Materials Response Units in the Gotthard Road-Tunnel
}

\author{
Norbert Cathomas*, Benno BühImann, Anton Mulle, Hermann Christen, and August Husner
}

\begin{abstract}
In the Gotthard tunnel, the transport of hazardous material is limited in quantity. The total amount of hazardous material has nonetheless increased in the last few years. The technical and organizational measures taken to deal with this fact are outlined in the following article. Moreover, problems related to a fire in a tunnel (those that are linked to an incident with chemical substances) will be addressed. Some of the most important findings arising from the fire of October 24, 2001 will be illustrated and some suggestions on how the fire brigade and the hazardous-materials response teams act in such cases will be presented.
\end{abstract}

Keywords: Fire fighting · Poisonous gases · Road-tunnel · Technical safety measures · Tunnel fire

\section{Risk Potential}

The potential risks for the north and south of the Gotthard tunnel lie - except for the densely populated southern part of Canton Ticino - mainly in rail and road transport. Hazardous goods may only be carried through the tunnel in limited quantities. In addition, if certain quantity thresholds are exceeded, the transport of these goods has to be approved or they are otherwise prohibited. Therefore, Canton Uri and Ticino have access to data regarding quantities of hazardous goods. This data shows that the transport and quantity of hazardous goods has increased in the last few years, without the inclusion of illegally transported material (Fig. 1).
${ }^{*}$ Correspondence: N. Cathomas Amt für Umweltschutz Uri

Klausenstrasse 4

CH-6460 Altdorf

Tel.: +41418752420

Fax: +41418752088

E-Mail: norbert.cathomas@ur.ch

www.chemiewehr-uri.ch

\section{Examples of Limited Quantities Transported Through the Gotthard Tunnel}

\section{Legal Basis}

ADR [1]: The second article states that apart from some excessively dangerous goods, other hazardous goods may be transported internationally in road vehicles that are subject to compliance with the conditions explained in Appendix A for the goods in question; in particular as regards to their packaging and labeling; and the conditions explained in Appendix B; in particular as regards the construction, equipment, and operation of the vehicle carrying the goods in question. The Swiss SDR [2] specifies, amongst other aspects, the types and quantities of hazardous goods permitted to be transported through the Gotthard tunnel.

Petrol can only be transported through the Gotthard tunnel up to a quantity of 501 . Special authorization from either Canton Uri or Ticino is required for quantities between 50 and 5001 , whereas quantities of more than 5001 are prohibited. Up to 51 of ethyl mercaptan can be carried without permission. Quantities between 51 and a maximum of 501 require special authorization, above is prohibited in the Gotthard tunnel. Transportation of a mixed load of substances is subject to authorization with respect to the total quantities: transport of
4001 of petrol (UN 1203) and 101 of nitrocellulose in solution (UN 2059) would be the maximum to be permitted by the relevant Canton Uri or Ticino.

According to the quantities of the hazardous goods transported, there is an increase in the risk of hazardous materials being involved in an accident. The entire freight traffic (including non-hazardous goods) has increased by 7-9\% per year. For safety reasons, the traffic has been restricted to approximately 4,000 vehicles in both directions per day since the day of the tunnel fire in 2001 (Fig. 2).

Fortunately, there have not been many incidents involving hazardous goods to date. Yet equally dangerous, and more common, are fires in tunnels. During large fires such as Mont-Blanc 1999, Gotthard 2001, or Tauern 2002, the danger of poisonous gases, poor vision, and limited oxygen supply is by no means less severe than in case of an accident with hazardous goods. Poisonous gases are composed of $\mathrm{CO}, \mathrm{CO}_{2}$, $\mathrm{HCl}, \mathrm{NO}_{\mathrm{x}}$, soot, and other traces of toxins such as PAK, dioxins, etc.

\section{Technical Safety Measures}

The main objective of these measures is to keep traffic flowing and, in case of problems, to provide the drivers with a safety area and (if necessary) with an escape.

The entire tunnel has safety areas that are built at regularly occurring intervals. 


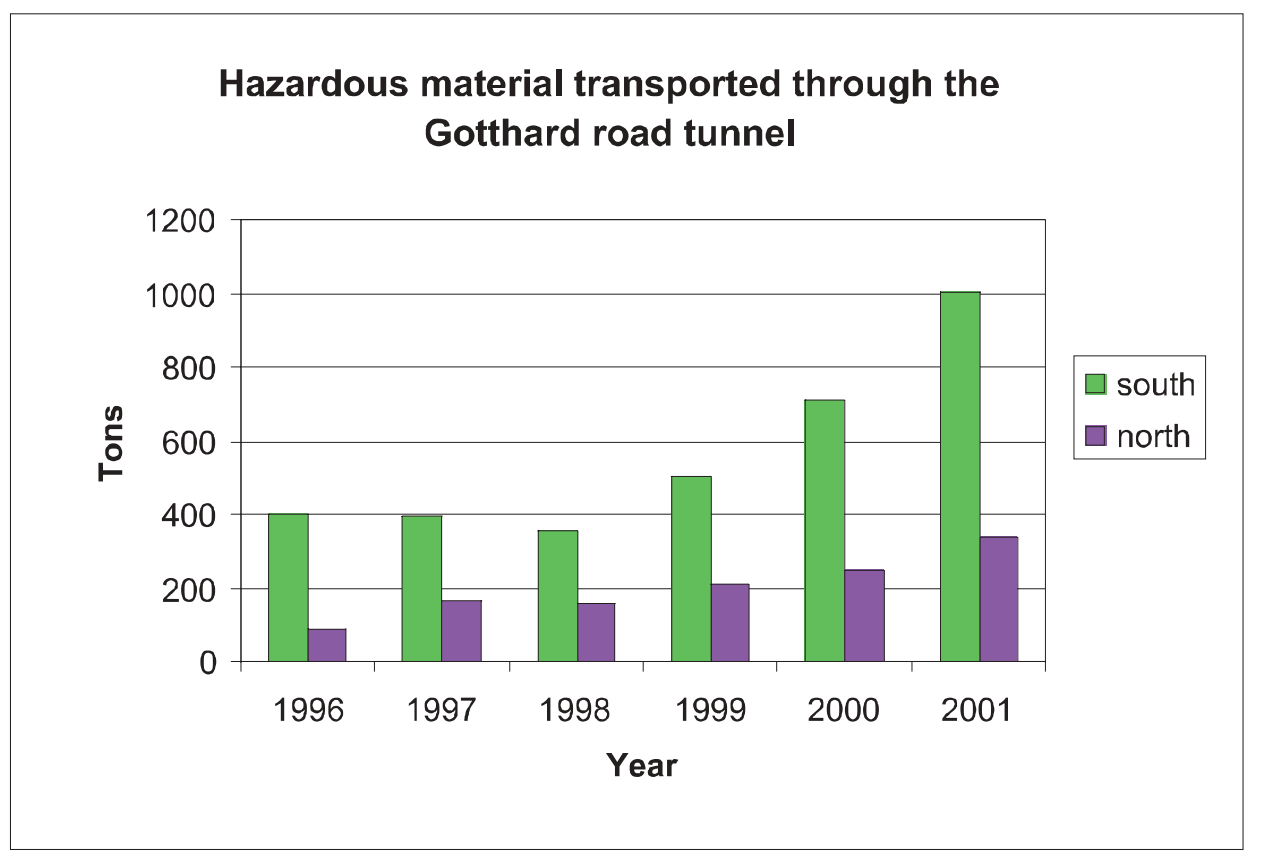

Fig. 1. The recorded and therefore authorized quantities of hazardous goods transported through the Gotthard tunnel have increased in both directions (north and south). Even in the year 2001, when the tunnel was closed for a period of two months due to a fire, it increased. (Source: Authorization of the Cantons; Evaluation of the Offices for Environmental Protection of Canton Ticino and Uri).

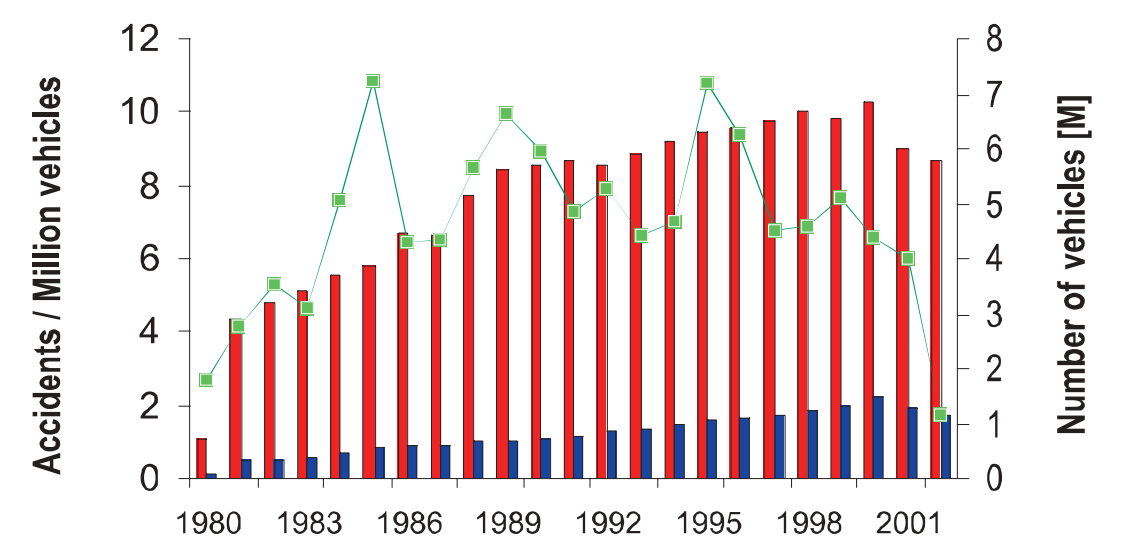

Vehicles total $\square$ Heavy vehicles $\rightarrow-$ Accidents / Million vehicles

Fig. 2. The total number of private cars as well as industrial vehicles in the Gotthard tunnel has increased up to the year 2000. In the year 2001, the tunnel was closed for two months due to a fire. Since the reopening of the tunnel, different measures have been taken in order to increase the safety of the people traveling through the tunnel (see text) which has drastically decreased the accident rate. (Source: Management of the Gotthard Tunnel and Fire Brigade ('Schadenwehr Gotthard')).

There are two fire extinguishers in each safety room and in each SOS-cabin and an emergency telephone that is directly linked to the central control station in Göschenen or Airolo. On the eastern side of the traffic lane there are a total of 64 rooms to shelter in and 11 lay-bys. On the western side there are 22 lay-bys (approximately one every
Every $250 \mathrm{~m}$, there is a door that leads to a safety room. On the other side of the safety room, another door leads to the security shaft. The security shaft as well as the safety rooms are ventilated with excessive pressure, which reduces the possibility of potential toxins and poisonous gases of entering from the traffic lane (Fig. 3).

Water supplies for the fire-brigade are located on the eastern side of the traffic lane at each of the safety rooms. The main pipe runs inside the security shaft and is supplied by water tanks that are located at each portal.

Further measures in the tunnel are

- Ventilation system: six ventilation stations supply fresh air and, in case of an accident, the required excessive air pressure.

- Radio reception: radio announcements are broadcast on three different FM frequencies and in four languages every 20 min or, in case of an accident, immediately.

- Information for the drivers: different traffic signs in four languages (e.g. to encourage the drivers to keep at a safe distance, etc.) and indications about escape routes are placed to inform the drivers and to increase their chance of escape. These large signs also bring variation into the driver's view and help to prevent him falling asleep.

- Monitoring of traffic: traffic is monitored by 68 traffic checkpoints with 85 cameras placed inside the tunnel and eleven monitors in the central control station in Göschenen and Airolo. Slow moving traffic and stationary vehicles are detected and signaled to the control center on duty.

- Emergency power supply: Electricity is supplied from the two portals. If power is down on one side (e.g. in the north), the other portal supplies the entire requirement of electricity. If both power stations are simultaneously unable to provide electricity, an emergency power supply is activated. This is able to supply energy to the infrastructure (traffic signs, emergency fresh-air ventilation, lights) for a period of $2 \mathrm{~h}$.

\section{Additional Measures in the Event of Fire - Implemented After the Fire of October 2001}

$750 \mathrm{~m}$ ) that have an SOS-cabin built next to them. Moreover, there are additional SOScabins every $125 \mathrm{~m}$. The SOS-boxes are monitored by camera. In the event of the use of a fire extinguisher, a signal is sent to the central control station.

The security shaft is built parallel to the tunnel on the eastern side of the traffic lane.
1) The entire traffic lane area/shaft is equipped with automatic fire safety lids. In case of a fire, the air draft in the particular area is reduced and the fire safety lids within $300 \mathrm{~m}$ of the fire area are opened automatically. Fire safety lids outside this area are then closed. 


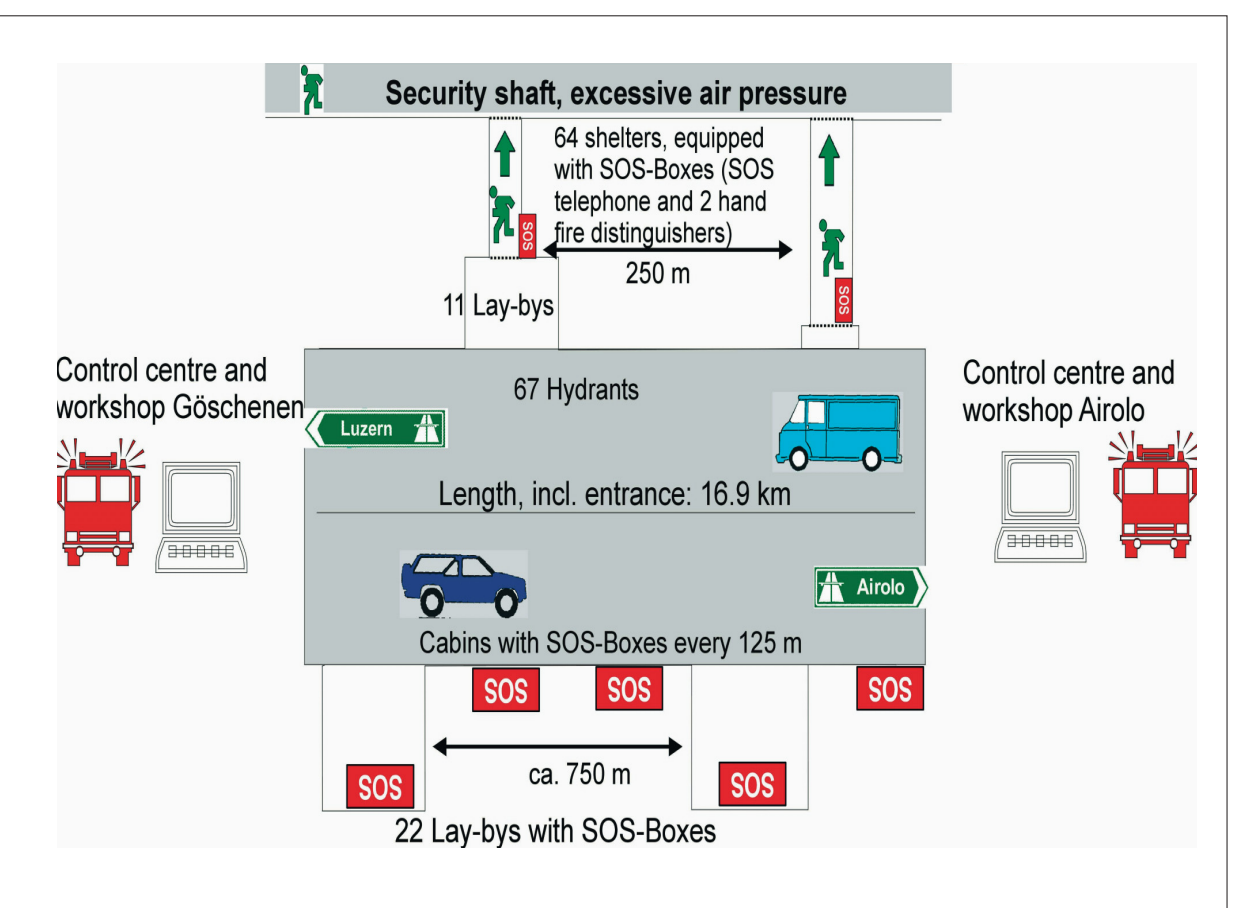

Fig. 3. Technical safety measures of the Gotthard tunnel

2) The entrances to the safety rooms are painted with special colors and therefore easier to recognize.

3) Special instructions about how to behave in case of an accident or a fire are broadcast on the radio in four languages every $20 \mathrm{~min}$. Information signs and colored direction indicators were set up.

4) Marks on the floor and traffic signs indicate the recommended distance between heavy vehicles, which must be maintained even in a traffic jam.

5) A deployment strategy has been created and will be tested for its practicality next year.

\section{Organizational Security Measures}

The traffic flow as well as the tunnel infrastructure are both controlled by two structurally identical central control stations in Airolo and Göschenen. As a result, each station can immediately take over in case of a system failure of the other station. One station controls the entire tunnel infrastructure and systems as well as the traffic flow for a period of two weeks, before supervision is given to the other station for the next two weeks.

Since 1980, there have been fire brigade bases at each portal, which are also part of and organized by the Gotthard Response Force. An emergency team comprising four officers is on duty $24 \mathrm{~h}$ a day, $365 \mathrm{~d}$ a year. It takes less than 3 min for the emergency team to be activated, i.e. to be on their way to the accident. Both fire brigade units are equipped with two water-tank vehicles (including additional rescue equipment) which are capable of changing the direction of travel in the tunnel using a built-in turret device. Moreover, the units are equipped with independent oxygen supplies (closed circuit breathing apparatus), which last up to $4 \mathrm{~h}$.

Primarily, the men on the team are employees of the workshops in Airolo and Göschenen. Since their main responsibility is the maintenance of the tunnel system and highways (except for the men of the fire brigade on duty), they are therefore extremely familiar with the tunnels. Many members of the Gotthard security force are also part of the local fire brigade. There are a total of 100 firemen available on both sides of the tunnel.

\section{Response Strategy}

The Swiss 'Chemiewehren' (hazardousmaterial response teams) can be compared with the TUIS-industrial fire brigade in Germany. However, the equipment and method of operation may vary depending on the geographical location. In the area of the Gotthard tunnel, the headquarters of the hazardous-material response teams are in Bellinzona (south) and Altdorf (north). The traveling times from Altdorf and Bellinzona to the tunnel of about 30 and 45 min, respectively, are somewhat long. As a result, the fire units at the north and south portal of the tunnel have been equipped and instructed to handle chemical incidents as well. The responsibility of the intervention team Gotthard (Schadenwehr Gott-
hard/Centro d'intervento San Gottardo) is to handle fire department duties during an incident with hazardous substances. However, the actual task of dealing with the chemicals involved will then be fulfilled by the hazardous-material response team based in Bellinzona and Altdorf. If the highway entrance to the Gotthard tunnel is jammed, the units approach the tunnel portal by using main roads. The equipment located in Göschenen and Airolo is sufficient for the personnel of the headquarters (Bellinzona and Altdorf) to handle a chemical incident, i.e. their staff could be simply flown to the portals by helicopter without the additional machinery or equipment.

The hazardous-material response teams of Uri include units of the fire brigade of the company Dätwyler AG and the fire brigade of Schattdorf as well as officers and instructors of other fire brigades. Chemical engineers and experts for ecology are recruited by the Office for Environmental Protection and integrated into these teams. This has the advantage that the experts are already members of the response team and do not have to be alerted first. Moreover, they are already familiar with the available equipment and strategy. Decisions regarding the severity of the environmental damage can be taken immediately.

\section{Deployment Strategy}

Alarm signals are set off:

- at SOS-notification stations in the tunnel and are transmitted to the central station;

- by drivers who call the police, i.e. the central alarm station of Canton Uri or Ticino;

- by self-triggering devices in the tunnel.

In the event of a fire or the potential for fire, the tunnel's fire units are alerted and approach the scene, depending on severity etc. from one or both sides of the tunnel. Their main tasks are to rescue people in danger, extinguish the fire, accompany the other drivers to the emergency exits, and transmit information and updates to the central control station. The central control station is responsible for the deployment of additional units, the supply of equipment and necessary material, and, in case of a chemical accident, alerting the hazardousmaterial response teams in Altdorf and Bellinzona.

In the event of a major incident, the following teams and units are deployed:

- ambulance and rescue teams (treat the injured);

- helicopter-rescue teams (transport injured);

- police (control traffic, inform the media); 
- local fire brigade (block streets to accident scene);

- locally based fire units (support of deployed units).

- hazardous-material response teams in Altdorf and Bellinzona (if hazardous materials are involved).

The response teams have their own meeting points and quarters on each side of the tunnel.

The tunnel ventilation extracts the toxins that occur during a fire or chemical leakage to the outside of the tunnel. Although these emission shafts are located in very scarcely populated areas, it cannot completely be ruled out that people or animals in the immediate vicinity of the shafts might be harmed. These emissions have been calculated and the consequences were assessed in the context of the emergency plan. The necessary steps, e.g. closing off the area, informing the local inhabitants, or the measurement of the air quality, are known to the intervention teams.

\section{Experience and Measures}

There has only been one chemical incident in the immediate vicinity of the tunnel, but not inside the tunnel itself. The worst incident so far was the fire of October 24, 2001. The experience gained from that event are described at this point:

The hazardous-material response teams of Canton Uri and Ticino were alerted and advised to support the fire brigade of the Gotthard tunnel and to measure the concentration of toxins.

In the central area of the fire, a high temperature remained even after the fire was extinguished. Only with the use of a large, mobile ventilator of the Canton Uri response team (which had to be transported across the Gotthard mountain), was it possible to cool down the area by dispersing fine spray.

Once an incident is over, a competent and knowledgeable authority has to officially reopen the tunnel for the units without protective gear and equipment. On October 24, 2001, this authority was given to the response team from Canton Uri. With the measurements of toxins (short-termtubes and $\mathrm{Ex} / \mathrm{O}_{2}$ measurements), it was possible to determine that there was no longer a particular chemical threat for the units to be deployed. Nonetheless, they were advised to wear dust masks and to remain in the tunnel only as long as necessary.

The structural damage (static stability of the tunnel ceiling) had to be assessed before more control units could be deployed. In the central area where the fire had been most destructive, the situation was not considered to be safe enough and the ceiling had first to be additionally supported.

The tragic balance of the accident was that eleven people died of suffocation due to the toxic gases of the fire. They were unable to find the lit entrances to the safety rooms in the darkness or were surprised by the rapidly spreading smoke wall while they were still in their cars. Dead bodies were found within $1.3 \mathrm{~km}$ of the center of the fire. The smoke cloud spread over a distance of $3 \mathrm{~km}$ north of the actual fire site. Twelve people suffered from symptoms of smoke poisoning.

\section{Traffic Safety Measures After the Fire}

- More checks on truck drivers regarding the safety and functionality of their vehicles as well as maximum loading capacity and quantities of hazardous goods. Accordingly, checkpoints on Swiss transit routes, where drivers are stopped and controlled, will be set up in the coming years.

- Maintaining a minimal distance of 150 $\mathrm{m}$ for trucks. The most efficient method turned out to quickly stop each vehicle at the entrance of the tunnel and thus force them to keep a safe distance.

\section{Problems}

1) The fire of October 24, 2001 demonstrated that toxic gases were responsible for a substantial number of the fatalities and injuries.

2) Although the safety infrastructure (shelters) in the tunnel was indicated, it was difficult to find them due to the extremely poor vision in the tunnel.

3) The drivers were only informed in the case of an emergency how to behave. There were no preventive measures at that time.
4) The potential for devastating fires increases with the quantity and frequency of heavy vehicles, especially if several trucks loaded with freight are driving right behind each other.

5) Only with precise organization and updated deployment schedule can efficient and quick deployment among the different security forces be guaranteed.

The technical and organizational measures that have been implemented since the fire of October 24, 2001 are described above.

\section{Tips}

Avoid breakdowns. Do you have enough petrol? (7\% of all breakdowns occur as a result of insufficient petrol). Switch on the radio when you enter the tunnel. Even in case of slow traffic or traffic jams, keep a distance of $50 \mathrm{~m}$ to the next car, so you can see what is happening in front of you.

\section{If Your Car Catches Fire...}

Try to leave the tunnel. If you are unable to do so, try to get to the next lay-by. Otherwise, roll on to the side of the traffic lane, leave the keys in the ignition switch, and walk to the closest shelter or the closest SOS-station.

1) Request first-aid

2) Try to put out the fire with the fire extinguisher available at the SOS-stations

3) Help the injured, if possible

4) Go to the nearest shelter

For further information about the Gotthard road tunnel, please visit the website: www.gotthard-strassentunnel.ch.

For the homepage of the hazardous-material response team Uri, please go to: www.chemiewehr-uri.ch.

Received: December 5, 2001

[1] Economic Commission for Europe, 'European Agreement concerning the International Carriage of Dangerous Goods by Road (ADR)', 1957, version 'ADR 2003', UNECE.

[2] Schweizer Bundesrat, 'Verordnung über die Beförderung gefährlicher Güter auf der Strasse (SDR)', 2002, SR 741.621. 